\title{
O Meu-Mundo e o Resto-do-Mundo
}

\author{
Arno Engelmann ${ }^{1}$ \\ Universidade de São Paulo
}

\begin{abstract}
Resumo
O presente artigo baseia-se na importante diferenciação entre meu-mundo e resto-do-mundo, ao contrário da simples constatação de um só Mundo ou Universo. Meu-mundo é o único ponto de partida de cada pessoa, inclusive dos investigadores científicos. Apresenta a duração de três segundos em média. Tudo que sobra é algo a ser inferido e constitui o resto-do-mundo para essa pessoa. Usando uma hipótese básica, a semelhança dos resto-s-do-mundo das diversas pessoas acham-se unidos em um só Universo. Contudo, a base biológica das pessoas age de tal maneira que a diferenciação acima mencionada é ignorada. Um produto dessa ignorância é o fato de a maioria dos pensadores da ciência cognitiva falarem em uma única consciência, quando é indispensável o contraste entre a minha consciência, que é essencialmente a mesma coisa que meu-mundo, e as consciências dos outros, partes minúsculas do resto-do-mundo. Além disso, a primeira consciência é de caráter filosófico e as segundas, de caráter científico.
\end{abstract}

Palavras-chave: Consciência; universo; mundo; evolução.

\section{My-World and the Rest-of-the-World}

\begin{abstract}
There is a very important difference between my-world and the rest-of-the-world. A contrary opinion is to register only a whole World or Universe. Each person begins necessarily in his my-world, even if he is a scientific researcher. The human myworld's duration is about three seconds. Anything outside this my-world is inferred. It constitutes the person's rest-of-theworld. According to a basic hypothesis, different persons' rest-s-of-the-world similarity can be united in a happening called the Universe. The person's biological background acts to disregard this difference. For example, the majority of cognitive science thinkers talk about having only one kind of consciousness. On the contrary, these thinkers have truly two kinds of consciousness: one through which they have immediate knowledge — my-world — and the other through which they have inference about human or nonhuman beings, very small parts of the rest-of-the-world. The first consciousness is philosophical; the second consciousnesses are scientific.

Keywords: Consciousness; universe; world; evolution.
\end{abstract}

$\mathrm{O}$ que se entende por mundo? $\mathrm{O}$ que se entende por meu-mundo e o que se entende pelo resto-do-mundo? Mundo é uma palavra portuguesa que deriva do latim mundus,-i. Mundus foi imitação literária feita pelos autores romanos da palavra grega kosmos. Kosmos, em grego antigo, apresenta dois significados diversos: o adjetivo limpo, elegante e um substantivo que quer dizer Universo ou $\mathrm{Mundo}^{2}$. Esses dois significados diferentes foram adotados pelos autores romanos. É, contudo, a palavra com significado de Universo que deu origem ao nosso Mundo, assim como a todas as palavras de significado parecido de quase todas as línguas neolatinas.

Entretanto mundo, com o passar dos tempos, adquiriu outros sentidos aparentados com o original. Por exemplo, pode-se falar em dois grandes mundos da Terra: o velho mundo, antes do Descobrimento(?) da América pelos europeus, e o novo mundo. Mundo neste caso é bem menor

\footnotetext{
${ }^{1}$ Endereço para correspondência: Rua da Consolação, 3617 ap. 42, CEP: 01416-001, Fone/Fax: (11) 3088.8759, São Paulo, SP.

E-mail: aengelmann@attglobal.net

${ }^{2}$ Universo ou Mundo, quando significam o único cosmo, vem com maiúscula; quando seu significado é diferente vem com minúscula.
}

que Universo. Ou significa classe social humana superior, quando se diz de uma pessoa que conseguiu ascender de classe, que conseguiu entrar no mundo. Ou ainda, os vários mundos que se apresentam nos diversos textos filosóficos. É nessa preocupação filosófica que iremos falar de agora em diante (Buck, 1949; Ferreira, 1999; Freire, 1939-1944; Lalande, 1993; Machado, 1967).

Mundo, no texto presente, significa o mesmo que Universo. Mundo, entretanto, colocado depois do pronome possessivo meu, isto é meu-mundo, quer dizer algo diferente. Esse mundo será apenas meu. Será tudo que eu percebo, imagino, penso no presente instante. Outras pessoas terão também o seu meu-mundo. Será, para cada pessoa, tudo que essa pessoa percebe, imagina, pensa no presente instante. Cada pessoa apresenta o seu meu-mundo. Em outras palavras, meu-mundo será diferente para cada indivíduo. Além disso, o fato de eu definir meu-mundo como tudo que é para mim no presente instante, estou rejeitando tudo aquilo que foi para mim em instantes diferentes da minha vida.

Ocorreria algo de semelhante entre os diversos meus-mundo-s de diferentes pessoas? Ainda que os meu-smundo-s de pessoas que moram na mesma cidade que 
eu se apresenta de modo parecido, o simples fato de exibir-se em cada indivíduo a parte pessoal de seu meumundo, torna necessariamente um pouco dissemelhante os meu-s-mundo-s de indivíduos únicos. Ou melhor, para cada indivíduo há uma parcela devida a inúmeros fatores de origem, de sexo, dos tipos de pais, do número ou da ausência de irmãos, de que a educação inicial veio da família próxima ou pelo contrário veio de diferentes pessoas que o acolheram na infância, do indivíduo se basear principalmente no que percebe exteriormente a ele ou de modo oposto basear-se principalmente em seus sentimentos internos, e não sei mais o quê. Essas maneiras influenciam o seu conjunto pessoal do presente momento.

Para cada pessoa que apresenta seu meu-mundo, resta a parte remanescente do mundo - o resto-do-mundo. Evidentemente esse resto-do-mundo será algo diferente para cada pessoa. Isso porque para cada pessoa, havendo o seu próprio meu-mundo, os meu-s-mundo-s de outras pessoas são apenas partes das consciências dessas outras pessoas e, portanto, partes dos seus seres humanos partes do resto-do-mundo. Entretanto, os vários resto-s-domundo são muito semelhantes ao Universo da época em que é apresentado e ainda muito semelhantes ao Universo das pessoas que constituem a mesma cultura ao qual pertence o indivíduo em questão.

Sei que a lógica presente de dividir o mundo em meumundo e o resto-do-mundo é muito estranha no linguajar comum e ainda mais estranha no campo das ciências empíricas. A maior parte dos cientistas ignora esta divisão. Entretanto, é a divisão que introduz uma marca individual em cada estudo de ciência empírica. Será o fundamento do artigo presente.

Vamos ver, em primeiro lugar, o que se entende geralmente por Mundo ou Universo e qual o lugar da consciência neste Mundo. A seguir, qual a posição de qualquer pessoa que procura conhecer esse Mundo, o seu iniciante meu-mundo. Há algo que resta e é a parte seguinte do artigo, o resto-do-mundo. Finalmente, qual o relacionamento que se estabelece entre meu-mundo e o resto-do-mundo, e o tipo de progresso que é possível graças a esse relacionamento.

\section{O Mundo ou Universo}

Em nosso ano de 2000 D.C., a aparência geral do Universo é a de um enorme espaço que contém cerca de dez por cento de galáxias ou quasares. Além disso, há uma parte do Universo formado de massa que não produz qualquer luz - a matéria escura. As galáxias variam de diâmetro, desde galáxias-anãs de cerca de cinco mil anos-luz $z^{3}$ até galáxias de rádio gigantes de cerca de três milhões de anos-luz. As galáxias normais grandes do tipo espiral, como a nossa Via Láctea, apresentam diâmetros de aproximadamente de cem mil a quinhentos mil anos-luz. As galáxias não apresentam distribuição uniforme no espaço. Grupos de galáxias relativamente vizinhas constituem aglomerados de galáxias. Por sua vez aglomerados de galáxias relativamente próximos constituem superaglomerados de galáxias. Não há evidência, até o momento, de aglomerados de superaglomerados de galáxias (Shu, 1994).

Dentro dos superaglomerados de galáxias, o nosso é chamado de Superaglomerado Local. Apresenta uma coleção de mais ou menos cem aglomerados de galáxias. Um desses aglomerados é o Aglomerado Local, aquele em que estamos. Exibe cerca de trinta cinco galáxias, dentre as quais duas gigantes e espirais: a Andrômeda e a nossa Via Láctea. As galáxias de tipo espiral mostram-se achatadas com uma parte central abaulada, que continua externamente com um disco achatado e, mais externamente, com dois bracos que apresentam uma estrutura de forma espiral. A Via Láctea contém cerca de cem bilhões de estrelas, além de poeira e gás. Uma dessas estrelas - o Sol — situa-se a cerca de dois terços do centro galáctico, na parte achatada externa (Hodge, 1994; Landy, 1999; Shu, 1994). As estrelas, as galáxias, os aglomerados de galáxias, os superaglomerados de galáxias encontram-se em movimento. Até recentemente, de acordo com a teoria do big-bang, a origem das galáxias teria decorrido quando da enorme explosão inicial, afastando-se, a seguir, uma da outra. Hoje em dia, muitos astrônomos pensam que grande número de aglomerados globulares seriam mais velhos que a data atribuída à grande explosão (Krauss, 1999).

O Sol apresenta um sistema de planetas que realizam a translação em sua volta. Recentemente, já se descobriu planetas em outras estrelas que não o Sol. A Terra é o terceiro dentro dos planetas solares, começando-se com o mais próximo do Sol. Visto nas dimensões das galáxias, a Terra seria um tenuíssimo microscópico grão de pó. Contudo, essa mesma Terra é nosso ponto de observação, a partir do qual vemos o que é possível dentro do Universo: planetas, estrelas, galáxias, aglomerados de galáxias, superaglomerados de galáxias.

A Terra, de maneira semelhante aos outros planetas solares, é formada em sua grande parte por constituintes minerais ${ }^{4}$. Além disso, possui uma pequena parte de constituintes vivos.

\footnotetext{
${ }^{3}$ Um ano-luz é a distância percorrida pela luz durante um ano, no vácuo e à velocidade de $300.000 \mathrm{~km} / \mathrm{seg}$.

${ }^{4}$ Gosto mais do adjetivo mineral do que o adjetivo não-vivo. $\mathrm{O}$ adjetivo nãovivo pressupõe uma negatividade afetiva desta palavra, que está longe de corresponder à realidade (Osgood, 1980).
} 
Aceitando-se a teoria da evolução darwiniana, os seres vivos mais complexos originaram-se de seres vivos mais simples através da seleção natural (Darwin, 1859/1958). Podemos dizer, hoje em dia, que através de mutações genéticas por acaso originaram-se modificações que resultam em indivíduos mais propícios a sobreviver do que aqueles que não passaram por estas mutações. Margulis e Sagan, além de mutações nos cromossomos, acreditam que os membros dos reinos ${ }^{5}$ originados depois do reino das bactérias, formaram-se a partir de simbioses dessas bactérias. Por exemplo, as mitocôndrias dentro do citoplasma de células superiores, transformando oxigênio em energia, são resultante de bactérias que vivem em simbiose com essas células. Apresentam $\mathrm{ADNs}^{6}$ próprios e reproduzem-se como bactérias, ainda que atualmente não possam viver de maneira independente (Margulis \& Sagan, 1995).

A atmosfera da Terra apresenta atualmente cerca de $21 \%$ de oxigênio. Essa composição não é aquela que se encontra nos planetas internos próximos, Vênus e Marte. Noventa e seis por cento da atmosfera de Vênus é de gás carbônico e 3\% de nitrogênio; $95 \%$ da atmosfera de Marte é de gás carbônico e 3\% de nitrogênio. $\mathrm{Na}$ atmosfera da Terra o nitrogênio sobe a 77\%. Mas o mais interessante é que o oxigênio molecular compõe $21 \%$ do ar. É um gás que normalmente se compõe com outras substâncias químicas. De acordo com muitos biólogos evolucionários, há cerca de setecentos milhões de anos atrás a composição da atmosfera terrestre começou a mudar. A grande quantidade de gás carbônico, que se encontra também nos planetas vizinhos, diminuiu de modo drástico, adquirindo com o tempo as proporções atuais: 3 partes em 10.000. Em compensação, o oxigênio aumentou. A composição da atmosfera da Terra alterouse quando as bactérias deram origem, principalmente por simbiose, a outros reinos contendo seres vivos terrestres que respiram oxigênio (Belton \& Malin, 1994; Chapman, 1994; Margulis \& Sagan, 1995; Squyres, 1994).

Qual a origem dos seres vivos? Pasteur demonstrou no século XIX que, no momento, a vida só poderia vir da vida. As comunicações anteriores sobre geração espontânea, como a de Aristóteles no século IV A.C. ou a de Buffon no século XVIII, caíram por terra. Entretanto, a sua origem por reorganização de substâncias minerais continua em voga (Cairns-Smith, 1985; Margulis \& Sagan, 1995).

\footnotetext{
${ }^{5}$ Reino, de acordo com os biólogos, é a primeira classificação dos seres vivos.

${ }^{6} \mathrm{ADN}$ é a abreviatura do ácido desoxirribonucléico. Os ADNs representam o código genético das células. $\mathrm{O}$ ADN do cromossomo seria um indicador que este fora antes uma célula independente.
}

Qual a melhor maneira de se representar o Universo? Há diversas maneiras de concebê-lo. Há teorias que concebem duas ou mais substâncias independentes. São teorias pluralistas. São exemplos a teoria dualista — matéria e mente - que teve sua origem em Descartes (1647/ 1967) ou a trialista - matéria, mente e produtos da mente humana - que foi sustentada por Popper e Eccles $(1977)^{7}$. No entanto, ao contrário, existem teorias que afirmam a existência de apenas uma única substância. São teorias monistas, e não materialistas ${ }^{8}$. Como exemplos mais importantes hoje em dia cito o reducionismo — redução de toda substância àquilo que são os elementos mais básicos, uma parte da disciplina física - e o emergentismo, do qual falarei a seguir.

O emergentismo, que me parece a explicação para a qual existe o maior número de observações científicas, concebe o mundo constituído de uma série de niveis de organização. Um nível de organização é diferente de outro se os princípios que o regem são diferentes do outro nível. Polanyi (1968) apresenta o exemplo de níveis para compreensão da fala. Em um nível se percebe os diversos sons da voz. Em outro nível se percebe a composição de palavras. Em um terceiro nível se percebe a constituição de sentenças. Em um quarto nível se percebe a constituição do estilo. Mas além disso a constituição de níveis pressupõe que eles se arrumem numa seqüência: que inicialmente há o nível dos sons, a seguir o de palavras, a seguir o de sentenças e, finalmente, o de estilo. Esses níveis obedecem a uma série de emergências. Essas emergências, esse passar de um nível a outro imediatamente superior, é a característica básica da teoria emergentista.

Tendo emergido um nível superior, pressupõe-se a concepção gestáltica deste nível em relação ao nível inferior. Esse ponto de vista é uma das versões do emergentismo. O reducionismo possível em outra das versões, isto é, a capacidade de passar-se completamente de um nível superior ao inferior, não existe na abordagem gestáltica (Arnheim, 1986; Engelmann, 1978b; Koffka, 1935; Köhler, 1920/1938, 1929/1947, 1960/1978; Scheerer, 1994).

Bertalanffy (1968/1977, 1972/1975) publicou diversos artigos nos quais fundamenta uma teoria emergentista, a

\footnotetext{
${ }^{7}$ Popper e Eccles (1977) não falavam em substâncias mas Mundos. Esses três Mundos, seguindo a nossa classificação, eram Mundo 1, Mundo 2 e Mundo 3.

${ }^{8}$ Apesar de a maioria dos autores monistas considerarem-se materialistas, eles tomam uma atitude de nomeação errada. Não são apenas aquilo que as teorias pluralistas chamam de matéria que seria inserido, mas também o que se concebe como pensamentos, pinturas, etc. É melhor utilizar o termo monismo.
} 
teoria geral de sistemas. A relação entre os diversos sistemas, que podem ser chamados de níveis, era gestáltica, ainda que Bertalanffy prefira o termo semelhante de todo. Há pensadores mais recentes, entre os quais me incluo, que aceitam a base gestáltica e aceitam que o Universo é explicado por uma série de níveis (Engelmann, 1997; Polanyi, 1968; Stadler \& Kruse, 1994).

Disse acima, que os níveis superiores não se reduzem totalmente a níveis inferiores. Entretanto, a irredutibilidade não é construída a partir de concepções pluralistas, como a de Popper e Eccles (1977). Pelo contrário, as determinações de um nível se dão em parte pelo outro nível dentro do Universo único. Durante muito tempo, era aceitável apenas explicar os níveis superiores por determinação dos inferiores. Por exemplo, as leis que determinam as propriedades das células continuam válidas ao serem estas partes da membrana mucosa do intestino de gatos. Hoje em dia, há inúmeras influências dos níveis superiores sobre aspectos dos níveis inferiores. Por exemplo, a estrutura óssea determina a calcificação das células que compõem os ossos (Campbell, 1974, 1990).

$\mathrm{Na}$ superfície da Terra encontram-se naturalmente os seres minerais e, também, os seres vivos. Dentro da moderna classificação de seres vivos de Whittaker (1969), modificada por Schwartz e Margulis (Margulis \& Sagan, 1995) e baseada na evolução, a divisão inicial é entre procariotos, com ausência de núcleos celulares e surgidos há cerca de três bilhões e novecentos milhões de anos atrás, e eucariotos, com presença de núcleos celulares e surgidos há cerca de um bilhão e novecentos milhões de anos atrás. Os eucariotos são representados pelos reinos que surgiram na seqüência evolucionária seguinte: (1) protoctistas - principalmente os chamados antes de protozoários -, (2) animais, (3) plantas e (4) fungos. Entre os animais, uma parte é constituída de vertebrados ${ }^{9}$. Entre os vertebrados, há os mamíferos; dentro dos mamíferos, há os primatas; dentro dos primatas, há os antropóides; dentro dos antropóides, há os hominóides; dentro dos hominóides, há a espécie e subespécie Homo sapiens sapiens ou ser humano ${ }^{10}$.

É nesse animal ser humano adulto que encontramos, pelo menos, uma parte do que hoje se chama de consciência. Consciência é a parte do ser vivo — ou pelo menos do animal ser humano adulto moderno - que o próprio ser vivo conhece. Esse conhecimento pode visar ou pretende visar informações sobre partes das coisas que ocorrem

\footnotetext{
9 A classificação zoológica dos vertebrados é de Storer (1951).

${ }^{10}$ Eduardo Ottoni, meu colega, me explicou que os pongídeos orangotango, gorila e chimpanzé - formam uma mesma família que os hominídeos - ser humano - segundo zoólogos mais modernos.
}

fora e/ou dentro desse ser vivo, no presente ou no passado. Além disso, esse conhecimento pode visar informar o próprio ser vivo de algumas de suas ações pretendidas ou presentes, reais ou imaginárias. A natureza desse conhecimento pode abarcar outras maneiras que não consegui captar ${ }^{11}$. De qualquer modo, a definição da consciência é o conhecimento pelo próprio ser vivo.

Há alguma relação entre emergência e o fato de o ser vivo apresentar consciência? Acho que sim. Há autores cuja única maneira de se representar de um lado o sistema nervoso central e de outro a consciência é a emergência. Essa emergência é apresentada como a existência de dois níveis. Assim, Sperry (1969, 1980/1983) ao querer introduzir uma consciência em interação com o cérebro, na sua nova versão de neurociência, achou que a única solução era a emergência. Essa é também a solução de Schwartz (1996) ao problema da consciência, ainda que esta seja apenas uma parte do problema mais amplo, o lugar da neurociência dentro da ciência empírica. Há autores que representam não apenas a consciência como parte do nível superior, mas além disso partes ditas nãoconscientes. Marcel (1988/1992) descreve duas distinções de processos que não cabem na consciência: os processos que descrevem o nível neural e o nível que, apesar de não-consciente, apresenta o mesmo tipo de descrição que os fatos conscientes - a descrição fenomênica ${ }^{12}$. Esses seriam os verdadeiros processos não-conscientes. Há autores que falam em diversas emergências nos seres vivos - células, tecidos, órgãos - parando no organismo, nível cujo limite externo é um eucarioto completo (Ayala \& Dobzhansky, 1974/1983; Dethier, 1984; Searle, 1992). Há autores que aceitam limites acima do organismo, como, por exemplo, o grupo, a sociedade (Bailey, 1998; Miller, 1978; Schwartz, 1982). Finalmente, há muitos autores que acreditam que a classificação em níveis não se restringe aos seres vivos, mas inicia-se com os seres minerais (Ali \& Zimmer, 1998; Goudge, 1967; Laszlo, 1975; Miller \& Miller, 1982; Needham, 1942; Novikoff, 1945; Scott, 1996). A emergência, não apenas caracterizando os seres vivos mas também todo o Universo, é a minha posição (Engelmann,1997).

\footnotetext{
${ }^{11}$ Consciência é o termo mais usado hoje em dia em português no sentido apresentado acima. Consciência é o termo que escolhi em meus trabalhos sobre o assunto. Nas línguas neolatinas, os termos descendem do latim conscientia, "conhecimento comum a diversas pessoas" para os antigos romanos. Em inglês, alguns autores utilizam consciousness com a mesma origem etimológica, outros empregam mind, outros awareness. Nas outras línguas há termos com a mais diversa origem etimológica.

${ }^{12}$ Descrições fenomênicas e fenomenológicas correspondem à descrição imediata.
} 
Pelo visto acima, há acontecimentos que se realizam no mesmo nível em que há fatos conscientes, mas que realmente não o são. Ao conjunto deles se dá o nome de fatos não-conscientes. Apresentam grande semelhança com os fatos conscientes. São provocados por estímulos de intensidades menores daqueles que normalmente levariam à consciência, como um som abaixo do limiar absoluto; ou são acontecimentos que um ser humano é incapaz de sentir por que está hipnotizado; ou são acontecimentos desagradáveis que aconteceram ao ser humano mas que foram reprimidos; ou, simplesmente, são acontecimentos que podem se apresentar à consciência, entretanto não o são no momento, como o gosto azedo de uma fruta que não se esteja atualmente comendo ou o conteúdo de um livro que nunca se leu. Finalmente, é possível que haja acontecimentos que nunca poderão ser conscientes, mas que se comportam do mesmo nível sistêmico dos acontecimentos conscientes. Todos esses acontecimentos são chamados de nãoconscientes. Portanto, há o nível superior à explicação neurofisiológica que é formado por acontecimentos nãoconscientes e acontecimentos conscientes. Dou a esse nível, de maneira semelhante a outros autores, o termo de mente $^{13}$ (Engelmann, 1997; Farthing, 1992; Sommerhoff, 1990).

Desde estudos relativamente antigos (Dixon, 1981) até investigações mais recentes (Kihlstrom, Barnhardt \& Tataryn, 1992; Lewicki, Hill \& Czyzewska, 1992; Mack \& Rock, 1998; Underwood, 1996; Weiskrantz, 1997), o ser humano é capaz de perceber e pensar sem estar consciente do que percebe e do que pensa. É esta capacidade de realizar inúmeras tarefas, que classicamente eram considerados conscientes, uma prova de que a consciência só se manifesta no ser humano? No excelente livro de Weiskrantz (1997), há investigações que demonstram que alguns mamíferos, como os chimpanzés, macacos não antropóides, ratos se comportam como se tivessem consciência.

Qual o animal, ou melhor, qual o ser vivo capaz de possuir consciência? A palavra consciência apresenta diversos sentidos ${ }^{14}$. Entretanto, há dois desses sentidos que são

\footnotetext{
${ }^{13}$ Mente era um termo que significava a parte oposta de matéria ou de corpo, na concepção dualista corpo-mente do ser humano. Há autores monistas, ou que acham o Universo constituído de uma única substância cartesiana, guardando o conteúdo antigo do conceito de mente. No século XX, com a importância crescente de uma série de processos não-conscientes, mente veio a ser o nome para englobar processos conscientes e nãoconscientes.

${ }^{14}$ Num artigo recente, falei na evolução de palavras a representar o conhecimento interno, da Grécia antiga até os dias de hoje (Engelmann, 1999).
}

largamente utilizados hoje em dia. No caso dos seres humanos, essa consciência pode incluir visões, audições, tactos, dores e também conteúdos de lembranças. Ao não termos esta consciência, não conhecemos absolutamente nada. Somos apenas máquinas. Há, além disso, a consciência que surge quando nos perguntamos o que conhecemos. É essa consciência que foi definida no fim do século XVII por Locke (1690/1975). É o fato de ser consciente de alguma coisa. Essa consciência pressupõe um en e um algo ou aparência. Esse eu vai perceber, vai se lembrar, vai pensar na aparência. Portanto, no primeiro caso, a consciência é da aparência; no segundo caso é dessa aparência e mais do eu que conhece essa sua aparência. No segundo caso eu sou consciente da aparência; no primeiro caso, apesar de conhecer a aparência, não tenho o que alguns chamam de consciência da aparência. O primeiro caso foi chamado de consciência primária por Edelman (1992) e Farthing (1992), como consciência 3 por Natsoulas $(1978,1983)$. O segundo caso foi chamado de consciência de ordem superior (Edelman, 1992), de consciência reflexa (Husserl, 1931/1953), de consciência refletiva (Farthing, 1992) ou de consciência 4 (Natsoulas, 1978, $1983)^{15}$.

Há pensadores que classificam como consciência apenas o segundo caso. É quando digo ou pelo menos penso que tenho consciência. Entretanto, o primeiro caso é muito muito mais amplo. E, de acordo com nossa definição e de acordo com o interesses de muitos pesquisadores é igualmente chamado de consciência.

Descartes $(1637 / 1988)$ apresentou no Discurso do Método a diferença entre os animais e os seres humanos. Os animais seriam máquinas muito mais aperfeiçoadas do que as máquinas feitas pelos seres humanos. Mas seriam máquinas. Os seres humanos, se pensarmos em sua parte corporal, também seriam máquinas. Entretanto, pelo fato de possuírem uma mente que foi feita por Deus, eram capazes de perceber e de agir de acordo com sua própria vontade.O que Descartes chamou principalmente de alma é hoje em dia conhecida como consciência. Portanto, para Descartes, a consciência seria puramente humana. Entretanto, há um trabalho recente de Daisie e Michael Radner (1996) que encontrou em textos posteriores de Descartes um lugar para uma consciência primária em animais. De qualquer modo, apesar da gigantesca contribuição de Descartes, da qual falarei mais adiante, a influência contrária a que se aceite acreditar em consciência de animais não-humanos continua.

\footnotetext{
${ }^{15}$ Baseando-se no Dicionário Inglês de Oxford, Natsoulas (1978, 1983) apresenta seis sentidos diferentes que foram ou estão sendo utilizados para a palavra consciousness. O terceiro e o quarto sentidos são importantes para a distinção acima mencionada.
} 
Griffin (1976) reabriu para os americanos, que leram textos behavioristas, a possibilidade de se estudar a consciência. E não se trata exclusivamente da consciência humana, mas das consciências de outros animais. Agora, que animais a serem incluídos? Carruthers (1998), por exemplo, clama que na realidade apenas a consciência de ordem superior ou reflexa seria capaz de originar consciência. Como consciência de ordem superior o único realmente pertencente é o ser humano. Talvez, entretanto, possa se incluir primatas superiores, como os chimpanzés. Para Edelman (1992) e Humphrey (1992) os mamíferos e as aves demonstram sistemas nervosos que poderiam abranger acontecimentos conscientes. Oakley (1985) acha que alguns répteis poderiam ser inseridos. Para Griffin (1992) não se trata apenas dos vertebrados superiores, mas também pode-se falar da consciência de insetos sociais. De outro lado, para Hameroff (1998), Insinna (1998) e Norris (1998), a consciência seria mais ampla: vários ou todos os seres vivos unicelulares apresentariam consciência. Para Margulis e Sagan (1995) ter consciência seria uma característica da autopoiêse das células: essas células reagem a seres minerais ou vivos situados fora da sua membrana e, portanto, apresentam consciência.

Em 1871, Darwin publicou um livro, The Descent of Man, no qual afirma que "É tão sem esperança procurarmos saber em que animais inferiores se iniciou o desenvolvimento das faculdades mentais, quanto realizarmos uma investigação para saber em que momento se iniciou a vida" (Darwin, 1871/1998, p. 67) ${ }^{16}$. Darwin achava que esse problema se destinava ao futuro. Essa mesma opinião foi levantada cento e vinte anos mais tarde por Freeman (1990). Minha atitude atual com relação ao problema é idêntica à antiga de Darwin e à mais nova de Freeman. É necessário conhecer um bom indicador da consciência nos seres vivos, antes de saber mais corretamente que seres vivos tem consciência e que seres vivos não a tem. Isso não é motivo para não colocarmos em seres vivos consciência em situações em que seres humanos adultos a utilizam. Bonobos, chimpanzés, gorilas e orangotangos podem ter a consciência reflexa. Tenho inúmeras observações minhas, chamadas de anedóticas, que demonstram que consciência é mais do que consciência reflexa e, pelo menos, para certos animais a consciência deve ser parte das maneiras de reagir ao seu exterior ${ }^{17}$.

\footnotetext{
16 Texto inglês traduzido por mim (Darwin, 1871/1998, p. 67).

17 As observações de Crick e Koch (1992), ainda que mostrem certos conjuntos de neurônios que oscilam na freqüência média de 40 hertz na indicação de consciência, não me parecem ainda suficientes para revelar quais os seres vivos a serem incluídos.
}

\section{Duas Abordagens ao Mundo}

Tudo o que falamos na parte O Mundo ou Universo deve ser considerado sob o ponto de vista estritamente científico. Há também assuntos em que não existem a abordagem científica que abordam esse mesmo Mundo. Entretanto, fala-se igualmente do conhecimento do Mundo.

Vejamos em outras áreas que não o conhecimento do Mundo exemplos desta duplicidade de abordagens. Uma pessoa quer construir a sua casa num terreno perto de um lago. No caso em que nunca se ocupou antes em atividades deste tipo, a primeira tarefa é chamar um arquiteto. Este arquiteto, diante da explicação da pessoa quanto ao número de indivíduos que moram com ele, quanto às atividades que pretende realizar na casa e quanto à sua própria maneira de verificar a beleza da futura edificação, apresenta um projeto arquitetônico para a pessoa. Essa abordagem é absolutamente necessária para o início da edificação. Porém, não é suficiente. Sem a atuação de pedreiros, que colocam as pedras uma em cima da outra, o projeto do arquiteto se perderia em suas fantasias. Essa segunda abordagem do pedreiro seria também absolutamente necessária. E seria mais básica.

Um outro exemplo é o de um escritor que vai escrever um conto a respeito de um casamento de duas pessoas que se conhecem desde crianças. Conforme for do seu interesse, vai ressaltar o aspecto mais formal do casamento ou o seu aspecto humorístico ou qualquer outro aspecto da questão. É a criação literária. É a abordagem que pensamos ser a única tarefa do escritor. Porém, há uma outra abordagem que é também absolutamente necessária. Quando o escritor era menor foi para a escola primária e aprendeu como se ligam certos sinais à noção de letras do português, como as palavras se formam da união de letras. Antes de saber como um conto vai ser constituído, ele aprendeu a escrever na sua língua materna. Essa abordagem de saber escrever é fundamental, e é mais básica. Neste exemplo, as duas abordagens foram do mesmo indivíduo.

A abordagem de investigar cientificamente um determinado objeto se torna possível se o indivíduo tem, consciente ou inconscientemente, uma abordagem epistemológica. As duas abordagens, a científica e a epistemológica, são absolutamente necessárias. A mais básica é a epistemológica.

\section{Meu-Mundo}

Cada ser humano conhece um mundo. Mas o mundo será conhecido de maneira algo diversa pelas diferentes pessoas. Por isso, é melhor verificar como uma pessoa conhece 
o mundo. Antes de procurar esta maneira de conjeturar sobre o mundo, quero fazer três breves digressões.

Em primeiro lugar, apresento uma questão de nomenclatura. No presente texto, falo em meu-mundo e resto-do-mundo. Em outro texto, falei em isto e fora (Engelmann, 1997). Os significados dos dois pares de termos é idêntico. Entretanto, a perspectiva é bem diferente. Isto é um termo baseado naquilo que se passa no presente de uma única pessoa; o fora é tudo aquilo que não é o isto. Esse fora é, no outro contexto, um quaseUniverso enorme, no qual o restante isto representa uma coisa micro-micro-...-microscópica. Nesse contexto, será melhor chamar o fora de resto-do-mundo e o isto de meu-mundo.

Em segundo lugar, falo em meu-mundo único. Esse meu-mundo não pertence a ninguém a não ser a mim. É uma coisa unicamente individual. Entretanto, ao discorrer sobre o meu-mundo espero que as minhas palavras sejam lidas por vocês. Cada um de vocês têm também um seu meu-mundo. O meu-mundo de você é apenas seu; nunca de outros e nunca o que chamei de meu meu-mundo. É, novamente, uma coisa individual. Se falarmos nas consciências presentes de seres humanos, essas consciências presentes, ainda que tenham algo de parecido com o meu-mundo, nunca serão os meu-s mundo-s. Então, como falar em meu-s mundo-s no plural? Por que falar nos meu-s mundo-s do enorme número de leitores? É uma forma apenas de linguagem. O que quero dizer é que posso falar no meu-mundo de outra pessoa e, mais ainda, falar nos diversos meu-s mundo-s que se pregam a diversas pessoas, ainda que corretamente só posso conscientizar o meu próprio meu-mundo.

Em terceiro lugar, acho importantíssimo colocar-me com uma posição dentro das questões filosóficas. Sou cético. Cético na linguagem atual comum significa Que, ou aquele que não crê, que duvida de tudo; descrente; desconfiado:..., no dicionário de Houaiss (1980, p. 181). Creio que não é exatamente assim.

Em filosofia há duas correntes com várias subdivisões cada uma: o dogmatismo, que afirma a existência de algumas verdades reais — os dogmas - e o ceticismo, que afirma que qualquer verdade, por mais universalmente aceita que seja, deve ser colocada em dúvida.

É o grande filósofo francês do século XVII, René Descartes (1647/1967), quem pôs em dúvida todos seus conhecimentos. Entretanto, escreve a partir da terceira parte de suas Meditações, que acreditava em alguns dogmas; o primeiro de todos é a existência de Deus (Williams, 1983). Como todo cientista, sou necessariamente cético. Esse ceticismo não implica a falta de crença em inúmeros aspectos que julgamos constantes no Universo. Esse ceticismo não implica a crença ou não-crença em Deus. Deus pode existir. Hume (1779/1947), o pai do ceticismo científico moderno, acreditava na existência de Deus; porém, não achava uma maneira de provar racionalmente a sua existência.

Entre os dogmáticos, há os realistas. Realista é aquele que acredita no dogma da realidade externa. Há alguma coisa fora de nós. Há diversos realistas, desde os realistas ingênuos, que acreditam na realidade daquilo que é proporcionado pela percepção, até os realistas indiretos, que acreditam em algo externo mas que não pode ser colocado exatamente por causa de falhas de nossa percepção e/ou de nossa cognição (Hirst, 1967).

De outro lado, há diversos tipos de céticos. Há o ceticismo pirrônico, que simplesmente duvida de todas as coisas, e há o ceticismo mitigado do filósofo do século XVIII David Hume (1748/1955). Hume também duvida de todas as coisas; entretanto, há coisas em que a dúvida é maior e coisas em que a dúvida é menor. Todavia, esse grau de dúvida pode mudar entre pessoas e pode mudar numa pessoa em vários períodos de sua vida. Considerando-se cético probabilista, Cournot, no século XIX, falava na probabilidade subjetiva ${ }^{18}$ ao explicar esse grau de dúvida. Sou cético mitigado ou probabilista. Apesar da eterna dúvida com relação a todas as coisas, essa dúvida pode apresentar graus diversos de probabilidade subjetiva. Há dúvidas que julgamos de máximas, há dúvidas que chamamos de grandes, e, além disso, há dúvidas médias, pequenas e mínimas (Cournot, 1851/ 1975; Engelmann, 1997; Lalande, 1993; Smith, 1992).

Voltemos, agora, ao tema principal do artigo. Meumundo é tudo que uma pessoa conhece num determinado instante. Também, é necessário acrescentar ao meu-mundo as vontades, os desejos, os pensamentos, as imagens da pessoa. O meu-mundo é presente, é imediato. Não é passado; pelo contrário, é o momento atual.

Sem dúvida, o momento, por menor que seja, apresenta uma certa duração. No entanto, para ser medido, precisa ser comparado com outras durações. Essas outras

\footnotetext{
${ }^{18}$ Cournot (1851/1975) distingue entre probabilidade matemática — a quantidade objetiva de um acontecimento dividida pela quantidade total de acontecimentos — e probabilidade subjetiva — a quantidade individual subjetiva de um determinado acontecimento. O grau desta probabilidade subjetiva não pode ser medida externamente, ainda que possua uma aceitação individual bem forte. Além disso, o grau de probabilidade subjetiva de um determinado acontecimento pode mudar com o tempo. Não existindo uma prova externa, a probabilidade subjetiva de um certo acontecimento apresenta-se apenas "maior" ou "menor" que outros acontecimentos; entretanto, não se sabe quanto é este "maior" ou "menor" na escala de números mais comum.
} 
durações não existem no meu-mundo. A única duração é aquela própria do meu-mundo.

O meu-mundo não pode ser conhecido através de uma série de processos causadores. Os processos, mesmo que sejam causadores do meu-mundo, poderão ser conhecidos somente através do meu-mundo. Por exemplo, sinto agora uma repentina dor em um dente molar direito. Sei que mastiguei erradamente desse lado. Meu dentista me havia prevenido contra o uso do lado direito. Mas, que posso fazer? Esqueci. Acho que a dor proveio do utilizar um dente que não poderia ser usado. O que sinto é a dor localizada, não a causa da dor. Se me explico, a causa da dor é posterior ao sentimento de dor. A própria explicação é uma fortíssima teoria. Entretanto, enquanto teoria pode estar errada. O que sinto no meu-mundo, em primeiro lugar, é a dor. Ou vejo agora a queda de um livro que estava na mesa do computador em direção ao chão. A queda desse livro ocorreu, já que algum fator rompeu o equilíbrio anterior. Sei que os livros pertencem a objetos desprovidos da capacidade de mover-se por atividade própria. Apesar de não conter no meu-mundo o lançamento do livro, o mais provável é que eu o tenha tocado com o cotovelo direito sem querê-lo. Entretanto, no meu-mundo vejo a queda de um livro. A provável explicação é posterior.

Tento transmitir-lhes o que entendo por meu-mundo. Isto é de um lado, extremamente fácil, mas de outro, extremamente difícil. É extremamente fácil compor o meu-mundo, já que é semelhante ao seu pseudo-meumundo de você. O seu meu-mundo é a única coisa que você conhece. É extremamente difícil, na medida que os textos científicos lidam com assuntos gerais e, enquanto gerais, não há lugar para o individual momentâneo. Os assuntos gerais são necessariamente parte do resto-domundo, são inferidos. Os assuntos gerais do resto-domundo pressupõem as inferências feitas por grande número de seres humanos observadores. Além disso, cada observador apresentará um número grande de observações. Cada observação possuirá para ele cada um de seus meu-s mundo-s da memória. E, enquanto partes da memória, serão também inferidos, não serão partes do meu-mundo dado imediatamente.

Quero valer-me da língua para dar-lhes algo da idéia daquilo que quero transmitir, nunca a transmissão propriamente da idéia. No entanto, espero que eu consiga dar-lhes o fundamento. É, no fundo, tão simples, tão claro.

A única coisa que eu verdadeiramente tenho é o meumundo. Acho que cada um de vocês terão uma coisa, apenas uma, que, usando a minha nomenclatura, chamarão também de meu-mundo. Voltando ao que já disse, meu- mundo é individual. E por ser individual, só poderei corretamente falar do meu-mundo, não do meu-mundo de você leitor. Vamos mencionar alguns exemplos para fortalecer a idéia daquilo que estou expondo.

Em primeiro lugar, vejo agora um quarto com duas estantes e um computador, com monitor e teclado. No teclado meus dedos estão digitando palavras, enquanto na tela do monitor essas palavras escritas estão surgindo em correspondência com aquilo que estou pensando. Essa é uma situação que todos reconheceriam como o presente. É o meu-mundo.

Em segundo lugar, posso imaginar a situação por que passei no hotel de Ribeirão Preto $^{19}$, numa manhã quando estava tomando café. Vi rapidamente uma pessoa que não esperava encontrar entre os psicólogos que em geral vêm à Reunião Anual. Entretanto, atualmente não vivo a situação do hotel, lembro-me apenas do que ocorreu. A memória pode enganar. Por exemplo, a lembrança de que realmente encontrei essa pessoa pode ser correta, mas o quando desse encontro pode estar errado. Não a encontrei num dia da última Reunião Anual de Psicologia, mas na penúltima Reunião Anual. Se me lembro agora melhor da situação, esse rápido encontro foi há bastante tempo. Uma outra hipótese, é que meu engano não foi registrado de maneira nenhuma na memória. Lembrome deste encontro numa manhã em que estive recentemente no hotel; entretanto, foi uma mera fantasia minha. A assim chamada lembrança, não foi uma lembrança; foi uma alucinação (Loftus, 1993). Tal tipo de erro é grave quando transferido a observações científicas.

Em terceiro lugar, posso pensar em Bombaim, uma grande cidade litorânea da Índia. Posso pensar em como eu ando nas ruas cheias de gente. Posso pensar em inúmeros animais andando também nas ruas — vacas, macacos, elefantes, etc. - e para os quais nenhum passante daria a menor atenção. É o que ouvi da Índia atual e o que acredito. Entretanto, nunca estive em Bombaim ou em qualquer outra cidade indiana. Não sei se um dia poderei estar por lá. Apenas posso imaginar a minha estadia nessa cidade. As imagens fazem parte do meumundo no momento em que as imagino.

Em quarto lugar, posso estar em casa e ouvir no rádio uma música popular. Uma música ou um discurso envolveriam mais tempo do que aquele que seria gasto durante a duração de um meu-mundo, duração ao redor de três segundos no ser humano (Fraisse, 1967; Pöppel, 1985/1988). Como é possível ouvir uma melodia relativamente longa, uma melodia que seria um todo para

19 Até 1998 todas as Reuniões Anuais eram em Ribeirão Preto. 
mim, se esse todo é maior que a duração do meumundo? Como seria possível ouvir uma pessoa contando uma ocorrência, se o contar a ocorrência seria maior do que a duração do meu-mundo? Acho que ao ouvir a música, ouço as diversas partes da melodia enquanto ela está ocorrendo e, ao mesmo tempo, percebo a configuração ou a Gestalt da música enquanto está se realizando. Acho que estou ouvindo as palavras enquanto estão ocorrendo e, ao mesmo tempo, estou reconstruindo a ocorrência e a ocorrência é mais longa do que o presente, o meu-mundo.

Meu-mundo é uma duração pequena na captação das Gestalten temporais. De outro lado, o meu-mundo que corresponde ao presente subjetivo na consciência dos outros seres humanos, é de tal maneira que dura mais ou menos três segundos. Os seres humanos apresentam a consciência, talvez, como o tempo necessário para reapresentar um objeto tendo como finalidade controlar e avaliar esse objeto, como escreve Crook (1980). Ou, quiçá, o tempo necessário para conscientizar um objeto no ser humano, e que é ao redor de três segundos, antes que se torne não consciente e caia na memória breve. Por que é assim? Não sei; mas é assim.

Esse motivo de tipo biológico precisa ser descoberto. De qualquer jeito, a consciência que surgiu nos seres vivos não pressupunha o uso filosófico-científico de ser o início da descoberta do Universo. Pelo menos, é o que penso atualmente sobre o assunto.

Em quinto lugar, posso sentir-me tenso. $\mathrm{O}$ artigo, a preocupação de transmitir bem um assunto para o qual pensei longamente, deu origem à emoção de tensão. Essa tensão que sinto, assim como outras emoções, teriam a mesma forma que percepções. O mais comum é que seriam sentidas por dentro da pele. Entretanto, além dessa localização interna, não há mais nada. Seriam chamados de estados internos ou subjetivos (Engelmann, 1978a). Sua origem específica estaria mais em atividades do sistema límbico, ainda que as conexões com nervos autônomos sejam importantes como sistemas sensoriais aferentes. Sentir-me tenso, tal como ver uma pessoa, seriam partes do meu-mundo.

Em sexto lugar, posso sentir-me agora calmo. Entretanto, posso lembrar-me de quanto estive tenso ontem no mesmo horário. Lembro bem desse fato. Inclusive, volto a viver, por poucos momentos, a mesma tensão. Tratar-se-ia, de novo, de ocorrências no meumundo.

Em sétimo e último lugar, posso pensar em resolver um problema matemático. Penso nisso, escrevo soluções prováveis, apesar do pensamento constituir a maior parte da solução de problemas. Qualquer atividade matemática, lógica, problemas científicos naturais são também parte do meu-mundo.

Nesses exemplos, mostrei algumas amostras do que poderia ser o meu-mundo. Há alguma coisa do que conheço diretamente ou conheci diretamente que não foram partes do meu-mundo? Pela definição que dei de meu-mundo, tudo que a pessoa conhece num determinado instante, a resposta é Não. Se, além de mim, incluir-se o conhecimento de todos os seres humanos, nessa época ou em outras épocas, esse conhecimento deve ter passado necessariamente por um meu-mundo. Esse conhecimento pode incluir tudo o que os psicanalistas pensaram sobre inconsciente, tudo o que foi pensado a respeito do conteúdo das possíveis consciências de animais não-humanos. Isso, evidentemente, foi ou é conteúdo de algum meu-mundo de pessoas humanas.

Tudo o que existe a respeito do conhecimento humano e forma parte das linguagens escritas ou de programações gráficas, fora antes, pelo menos uma vez, incluído em qualquer meu-mundo de um produtor. $\mathrm{E}$ daí pode ser incluído nos meu-s mundo-s do enorme número de leitores. Todo e qualquer conbecimento bumano passou, nem que seja uma única vez, num meu-mundo.

Como o meu-mundo é a forma real de conhecimento, quais os limites desse conhecimento? Tudo o que se percebe, mas não os caminhos que levam fisiologicamente ao percepto ${ }^{20}$ - desde os órgãos de sentidos que transformam os estímulos visuais, auditivos, olfativos, tácteis em informações nervosas que são transmitidas da periferia para partes mais centrais do sistema nervoso central; nem as formas de ondas eletromagnéticas, de ondas harmônicas, dentro de vinte a vinte mil ciclos por segundo nos seres humanos; de moléculas voláteis que se propagam no ar até os narizes; das formas sólidas e líquidas que atuam nos receptores de tacto; nem a constituição dos objetos externos que são percebidos. Além do que se percebe, tudo o que se imagina, mas não aquilo do que se quer ter uma imagem ${ }^{21}$ — as lembranças das ocorrências, não as ocorrências em si que apareceram antes e não formam mais partes do meu-mundo presente; as imagens de ocorrências que no futuro, espero, sucederão ao presente meu-mundo e não o caminho no qual vou realmente andar depois de ter concluído a redação; as imagens que realizo para verificar se mudando a posição

\footnotetext{
${ }^{20}$ Percepto é uma palavra pouco usada em português. Significa o conteúdo consciente da percepção (Ferreira, 1999; Prado e Silva, 1970).

${ }^{21}$ Imagem é o conteúdo consciente. Não deve ser confundido com imaginação, que pretende mostrar partes futuras que contêm além das imagens, perceptos, pensamentos e não sei que mais (White, 1990).
} 
de duas figuras bidimensionais de dois objetos tridimensionais poderia chegar à conclusão que realmente se trata do mesmo objeto tridimensional e não a mudança efetiva no espaço tridimensional desses dois objetos.

$\mathrm{E}$, muito provavelmente, tudo o que se pensa. Há muita controvérsia sobre a realidade consciente daquilo que se pensa. A maioria dos investigadores hodiernos acreditam que o conteúdo do pensamento constitui parte da consciência. No entanto, há pesquisadores que acham que o pensamento se traduz sempre por imagens (Mandler \& Mandler, 1964). Atualmente se crê que o indivíduo que pensa está numa consciência reflexiva e não numa consciência primária, como disse antes. Ele reflete sobre o conteúdo da consciência primária. Nessa reflexão, ele pensa sobre algo que forma uma aparência para o eu (Farthing, 1992; Husserl, 1950). Sommerhoff (1990) considera essa forma de consciência uma representação de ordem superior à representação interna do mundo e do eu-no-mundo ou à representação de objetos, eventos e situações fictícias ou ausentes. A divisão é contudo mais ou menos a mesma que, há trezentos e cinqüenta anos, Descartes (1649/1989) realizava entre paixões, que corresponderiam à consciência primária, e ações, que corresponderiam à consciência reflexiva.

É importante que freqüentemente os pensamentos não constituem parte da consciência reflexiva mas da consciência primária. O que distingue os dois é a maneira de se apresentar ao meu-mundo: a consciência primária parece $d a d a$; a consciência reflexiva é meu-mundo que $f a$ :

Havia dito há nove anos que meu-mundo é percebido

"sem um corpo. Ao mesmo tempo, posso pensar que tenho um corpo; ... Posso cortar-me e o meu sangue irá se esvair. Mas, o sangue é somente um líquido vermelho, não é o sangue do que falam os fisiólogos. As pessoas que posso perceber, os animais que posso perceber, as plantas que posso perceber, as partes do meu escritório, a janela, o que vejo diante da janela — prédios com apartamentos, o barulho de pessoas que falam mas que não vejo — tudo isso é real, mas real enquanto aparência. Não posso ir além do que me faculta a percepção. Posso pensar sobre as causas prováveis dessas percepções, posso pensar em assuntos os mais diversos. Entretanto, são apenas pensamentos. Posso imaginar. Parte dessas imagens são lembranças. Mas não sei qual a origem das imagens, como não sei quais as origens das percepções, como não sei qual a origem dos pensamentos" (Engelmann, 1991, pp.48-49)

\section{O Resto-do-Mundo}

O resto-do-mundo é a parte inferida que cada pessoa observa fora do seu meu-mundo. Essas inferências obedecem à formação de hipóteses. Na minha filosofia, há algumas hipóteses básicas ${ }^{22}$ que antecedem quaisquer outras hipóteses (Engelmann, 1997). Dentro dessas hipóteses, é principalmente importante a terceira ou hipótese do universo comum, que considera a semelhança de todos os restos-do-mundo, tanto presentes quanto passados. Isto é, ainda que as observações do resto-domundo das diferentes pessoas não sejam exatamente iguais, as diferenças de percepção podem ser atribuídas às pessoas e não ao mundo exterior. E portanto, aceita esta terceira hipótese, o mundo exterior seria real.

A afirmação acima, com o verbo ser no presente do indicativo, é o fundamento do realismo. Entretanto, essa afirmação é, considerada por mim, uma hipótese. Daí, como hipótese, ela faz parte do ceticismo.

Aceita a terceira hipótese básica ou hipótese do universo comum - e aceitas as seis outras hipóteses básicas - tudo o que dissemos na primeira parte do artigo, vai referir-se também à parte presente. $\mathrm{O}$ restodo-mundo, com as ressalvas próprias da introdução do ceticismo probabilístico, é o Mundo ou o Universo.

\section{Relações Entre Meu-Mundo e o Resto-do-Mundo}

Qual a relação que se estabelece para cada pessoa entre seu meu-mundo e seu resto-do-mundo? Basicamente, a relação é feita entre seu meu-mundo fenomenicamente imediato e seu resto-do-mundo inferidamente mediato. Seu resto-do-mundo passa através de hipóteses. Como disse há pouco, a relação é entre o meu-mundo e, tendo afirmado as hipóteses básicas, é o Universo cientificamente aceito no ano de 2000 DC. Para qualquer pessoa, não importando a época de sua vida, existiria sempre a divisão entre seu meu-mundo e o Universo tal qual aceito por essa mesma pessoa.

Muitas dialéticas foram apresentadas para compreender o mundo. Acho que uma dialética a mais deveria ocorrer entre o minúsculo meu-mundo, de um lado, e o enorme Universo, de outro. Mesmo que esta dialética capte a diversidade enorme de tamanhos das duas coisas, deve principalmente mostrar duas maneiras diversas de conhecimento.

Além dessa duplicidade de conhecer, há uma outra questão a ser debatida. As pessoas com as quais se tem

\footnotetext{
${ }^{22}$ As sete hipóteses básicas são, em ordem decrescente de probabilidade subjetiva, (1) hipótese fundamental; (2 ) hipótese da duração; (3) hipótese do universo comum; (4) hipótese da ordem; (5) hipótese da divisão dos acontecimentos em fatuais e teóricos; (6) hipótese da divisão dos acontecimentos fatuais em superficiais; e profundos; e, (7) hipótese da divisão dos acontecimentos fatuais profundos em dinâmicos e estáticos (Engelmann, 1997). Mudei a ordem decrescente, colocando a hipótese da ordem em quarto lugar.
} 
contato apresentam suas consciências. De um lado, a consciência da pessoa deve ser localizada em parte do seu organismo, um dos níveis do seu ser biológico. De outro lado, o meu-mundo é também conhecido como consciência. Entretanto, como deixei bastante claro no artigo Dois tipos de consciência (Engelmann, 1997), os locais apresentam-se totalmente diferentes dentro da cadeia científica. A minha consciência é sempre o início de qualquer observação científica. As consciências de outras pessoas são locais de probabilidade subjetiva alta dentro do nível organismo de seres humanos, mas partes do resto-do-mundo. Falo em consciência-imediata no caso de meu-mundo; falo em consciência-mediata-de-outros no caso de porções do organismo de alguns ou todos os animais ${ }^{23}$.

Há um grande número de investigadores e pensadores que continuam adotando o critério anterior ao acima citado: haveria apenas um tipo de consciência. Essa consciência para muitos deles seria subjetiva, seria a capacidade de captar qualia ${ }^{24}$, e ao mesmo tempo de comportar-se como um ser humano externo a nós. Entretanto, já faz sessenta e oito anos que o psicólogo Edward C. Tolman (1932/1967, 1935/1951) escreveu sobre a enorme diferença que existe entre esses duas formas de consciência ${ }^{25}$.

Podemos dar graças por ter o ser humano descoberto uma maneira de, dado o seu minúsculo meu-mundo, explorar inúmeras facetas do resto-do-mundo. Daí, à medida que foi descobrindo o resto-do-mundo, inventava engenhos capazes de facilitar seu trabalho, inventava preparações para melhorar os seus alimentos, inventava remédios para alongar a sua vida, inventava aparelhos que facilitavam os seus deslocamentos na superfície da Terra. E, finalmente, pensava em arquiteturas que qualificassem sua passagem na Terra, pensava em músicas e pinturas que expressassem os seus sentimentos, pensava em utopias capazes de melhorar a vida dos seus semelhantes. Essas utopias, quando aceitas pela maioria dos seres humanos, poderão levá-los a melhorar a organização de sua sociedade.

\footnotetext{
${ }^{23}$ Há, também, a consciência-mediata-do-observador, consciência que vem ao observador por inferência de suas lembranças.

${ }^{24}$ Qualia é o plural de quale. Quale é a palavra latina que compreende as diferenças qualitativas de maneira semelhante ao quantum que se refere às diferenças quantitativas. Ser consciente é ter qualia, como diz Stubenberg (1996). Para mim ter consciência-imediata é ter qualia; ser um ser humano com consciência-mediata-de-outros não é ter qualia mas um tipo de acontecimentos semelhante a outros tipos de acontecimentos, como os que se dão nos músculos, nos grupos de formigas, etc.

${ }^{25}$ Tolman utilizava dois termos diferentes para qualificar as duas consciências: immediate experience para consciência-imediata e consciousness para consciência-mediata-de-outros. Entretanto, a sua utilização é quase idêntica à minha.
}

Esse resto-do-mundo é um mundo em que a ciência penetra cada vez mais, esse resto-do-mundo é um mundo em que a moral pode possuir possibilidades de melhorar a vida de todos os seres humanos. Entretanto, sem os acreditáveis meu-s-mundo-s de bilhões de pessoas, não se poderia inferir absolutamente nada sobre os restos-do-mundo. Tudo o que se constrói a respeito do mundo, ou melhor dos resto-s-do-mundo, foi conseguido a partir de meu-s-mundo-s individuais. São indivíduos ou melhor, em última instância, momentos de indivíduos que fabricam o nosso Universo.

\section{Referências}

Ali, S. M. \& Zimmer, R. M. (1998). Beyond substance and process: A new framework for emergence. Em S. R. Hameroff, A . W. Kaszniak \& A. C. Scott (Orgs.), Toward a science of consciousness II (pp. 585-592). Cambridge: MIT Press.

Arnheim, R. E. (1986). The trouble with wholes and parts. New Ideas in Psychology, 4, 281-284.

Ayala, F. Y. \& Dobzhansky, T. (Orgs.) (1983). Estudios sobre la filosofía de la biología (C. P. Rotge, Trad. do inglês para o espanhol). Barcelona: Ariel. (Original publicado em inglês em 1974)

Bailey, A. (1998). The five kinds of levels of description. Em S. R. Hameroff, A. W. Kaszniak \& A. W. Scott (Orgs.), Toward a science of consciousness II (pp. 577-583). Cambridge: MIT Press.

Belton, M. J. S. \& Malin, M. C. (1994). The solar system. Mars. Em P. B. Norton (Org.), The new encyclopaedia Brittanica. (Vol. 27; pp. 493-502; 15 ed.) Chicago: Encyclopedia Brittanica.

Bertalanffy, L. von (1975). The history and development of general system theory. Em L. von Bertalanffy (Org.), Perspectives on general system theory (pp. 149-169). New York: George Braziller. (Original publicado em 1972)

Bertalanffy, L. von (1977). Teoria geral dos sistemas (F. M. Guimarães, Trad.). Petrópolis: Vozes. (Original publicado em inglês em 1968)

Buck, C. D. (1949). A dictionary of selected synonyms in the principal Indo-European languages. Chicago: University of Chicago Press.

Cairns-Smith, A. G. (1985). Seven clues to the origin of life. Cambridge, UK: Cambridge University Press.

Campbell, D. T. (1974). 'Downward causation' in hierarchically organized biological systems. Em F. J. Ayala \& T. Dobzhansky (Orgs.), Studies in the philosopby of biology (pp. 179-186). New York: Macmillan.

Campbell, D.T. (1990). Levels of organization, downward causation, and the selection-theory approach to evolutionary epistemology. Em G. Greenberg \& E. Tobach (Orgs.), Theories of the evolution of knowing (pp. 1-17). Hillsdale, NJ: Lawrence Erlbaum.

Carruthers, P. (1998). Animal subjectivity. Psyche, 4(3), 1-7.

Chapman, C. R. (1994). The solar system. Earth. Em P. B. Norton (Org.), The new encyclopaedia Brittanica. (Vol. 27; pp. 477-481; 15 a ed.) Chicago: Encyclopaedia Brittanica.

Cournot, A. A. (1975). Essai sur les fondements de nos connaissances et sur les caractères de la critique philosophique. Paris: J. Vrin. (Original publicado em 1851)

Crick, F. \& Koch, C. (1992). The problem of consciousness. Scientific American, 267(3), 110-117.

Crook, J. H. (1980). The evolution of human consciousness. Oxford, UK: Clarendon Press.

Darwin, C. (1958). The origin of species. New York: New American Library of the World. (Original publicado em 1859)

Darwin, C. (1998). The descent of man. Amherst, NY: Prometheus. (Original publicado em 1871) 
Descartes, R. (1967). Les méditations. Em F. Alquié (Org.), Euvres philosophiques de Descartes. Tome II (pp. 375-1073). Trad. do latim pelo duque de Luynes. Paris: Garnier. (Original publicado em 1647)

Descartes, R. (1988). Discours de la méthode. Em F. Alquié (Org.), Euvres philosophiques de Descartes. Tome I (pp. 167-650). Paris: Bordas. (Original publicado em 1637)

Descartes, R. (1989). Les passions de l'âme. Em F. Alquié (Org.), Euvres philosophiques de Descartes. Tome III (pp. 939-1103). Paris: Bordas. (Original publicado em 1649)

Dethier, V. G. (1984). Levels of behavior and emergent mechanisms. Em G. Greenberg \& E. Tobach (Orgs.), Behavioral evolution and integrative levels (pp. 121-132). Hillsdale, NJ: Lawrence Erlbaum.

Dixon, N. (1981). Preconscious processing. Chichester, UK: John Wiley.

Edelman, G. M. (1992). Bright air, brilliant fire: On the matter of the mind. New York: Basic Books.

Engelmann, A. (1978a). Os estados subjetivos. São Paulo: Ática.

Engelmann, A. (1978b). Introdução. Em A. Engelmann (Org.), Wolfgang Köbler (pp. 5-36). São Paulo: Ática.

Engelmann, A. (1991). A possibilidade do estudo científico da consciência. Tese de livre-docência não-publicada, Departamento de Psicologia Experimental, Instituto de Psicologia, Universidade de São Paulo. São Paulo, SP.

Engelmann, A. (1997). Dois tipos de consciência: A busca da autenticidade. Psicologia USP, 8(2), 25-67.

Engelmann, A. (1999). Palavras que indicam conhecimento do próprio animal. Em M. do C. Guedes \& R. H. de F. Campos (Orgs.), Estudos em bistória da psicologia (pp. 13-31). São Paulo: EDUC.

Farthing, G. W. (1992). The psychology of consciousness. Englewood Cliffs, NJ: Prentice Hall.

Ferreira, M. B. (1999). Aurélio Século XXI (3 $3^{\mathrm{a}}$ ed.). Rio de Janeiro: Ed. Nova Fronteira.

Fraisse, P. (1967). Psychologie du temps. (2a. ed.) Paris: P.U.F.

Freeman, W. J. (1990). On the fallacy of assigning an origin to consciousness. Em E. R. John (Org.), Machinery of the mind (pp. 14-26). Boston: Birkhäuser.

Freire, L. (1939-1944). Grande e novíssimo dicionário da lingua portuguesa, Vols. 1-5. Rio de Janeiro: A Noite.

Goudge, T. A. (1967). Emergent evolutionism. Em P. Edwards (Org.), The encyclopaedia of philosophy (Vol. 2; pp. 474-477). New York: Macmillan \& Free Press.

Griffin, D. R. (1976). The question of animal awareness. New York: Rockfeller University Press.

Griffin, D. R. (1992). Animal minds. Chicago: University of Chicago Press.

Hameroff, S. R. (1998). Did consciousness cause the Cambrian evolutionary explosion? Em S. R. Hameroff, A. W. Kaszniak \& A. C. Scott (Orgs.), Toward a science of consciousness II (pp. 421-437). Cambridge: MIT Press.

Hirst, R. J. (1967). Realism. Em P. Edwards (Org.), The encyclopedia of philosophy. (Vol. 7; pp. 77-83). New York: MacMillan.

Hodge, P. W. (1994). Galaxies. Em R. Mc Henry (Org.), New encyclopaedia Britannica. Macropaedia. (Vol. 19; pp. 611-637; 15a ed.) Chicago: Encyclopaedia Britannica.

Houaiss, A. (1980). Pequeno dicionário enciclopédico Koogan Larousse. Rio de Janeiro: Larousse do Brasil.

Hume, D. (1947). Dialogues concerning natural religion. Indianapolis: Liberal Arts. (Original publicado em 1779)

Hume, D. (1955). An inquiry concerning buman understanding. Indianapolis: Liberal Arts. (Original publicado em 1748)

Humphrey, N. (1992). A history of the mind. London: Chatto \& Windus.

Husserl, E. (1950). Ideen zur einer reinen Pbänomenologie and phänomenologischen Philosophie. Haia: Martinus Nijhoff.

Husserl, E. (1953). Méditations cartésiennes (G. Peiffer \& E. Levinas) Trads. do alemão, na época não publicado, para o francês. (Original publicado em 1931)
Insinna, E. M. (1998). Nonlinear dynamics in the photoreceptor of the unicellular alga Euglena gracilis: An application to the evolutionary aspects of consciousness. Em S. R. Hameroff, A. W. Kaszniak \& A. W. Scott (Orgs.), Toward a science of consciousness II (pp. 407-420) Cambridge: MIT Press.

Kihlstrom, J. F., Barnhardt, T. M. \& Tataryn, D. G. (1992). The psychological unconscious: Found, lost, and regained. American Psychologist, 47, 788791.

Koffka, K. (1935). Principles of gestalt psychology. London: Routledge \& Kegan Paul.

Köhler, W. (1938). Physical gestalten. Em W. D. Ellis (Org.), A source book of gestalt psychology (pp. 17-54; W. D. Ellis, Red. e Trad.) London: Routledge \& Kegan Paul. (Original publicado em alemão em 1920)

Köhler, W. (1947). Gestalt psychology (2a. ed.). New York: Liveright. (Original publicado em 1929)

Köhler, W. (1978). O problema mente-corpo. Em A. Engelmann (Org.), Wolfgang Köbler (pp. 129-147; J. S. de C. Pereira \& V. L. Bianco, Trads.). São Paulo: Ática. (Original publicado em inglês em 1960)

Krauss, L. M. (1999). Cosmological antigravity. Scientific American, 280(1), 34-41.

Lalande. A. (1993). Vocabulário técnico e crítico da filosofia (Trads. do francês) F. S. Correia, M. E. V. J. Aguiar, E. Torres \& M. G. Souza. São Paulo: Martins Fontes.

Landy, S. D. (1999). Mapping the universe. Scientific American, 280(6), 30-37.

Laszlo, E. (1975). The meaning and significance of general system theory. Behavioral Science, 20, 9-24.

Lewicki, P., Hill, T. \& Czyzewska, M. (1992). Nonconscious acquisition of information. American Psychologist, 47, 796-801.

Locke, J. (1975). An essay concerning buman understanding. Oxford, UK: Oxford University Press. (Original publicado em 1690)

Loftus, E. (1993). The reality of repressed memories. American Psychology, 5, 518-537.

Machado, J. P. (1967). Dicionário etimológico da lingua portuguesa. (2 ed.) São Paulo, Lisboa: Livros Horizonte, Editorial Confluência.

Mack, A. \& Rock, I. (1998). Inattentional blindness. Cambridge, MA: MIT Press.

Mandler, J. M . \& Mandler, G. (Orgs.) (1964). Thinking: From association to gestalt. New York: John Wiley.

Marcel, A. J. (1992). Phenomenal experience and functionalism. Em A. J. Marcel \& E. Bisiach (Orgs.), Consciousness in contemporary science. Oxford: Oxford University Press. (Original publicado em 1988)

Margulis, L. \& Sagan, D. (1995). What is life? New York, NY: Simon \& Schuster.

Miller, J. G. (1978). Living systems. New York: McGraw-Hill.

Miller, J. G. \& Miller, J. L. (1982). The earth as a system. Behavioral Science, 27, 303-322.

Natsoulas, T. (1978). Consciousness. American Psychology, 33, 906-913.

Natsoulas, T. (1983). Concepts of consciousness. Journal of Mind and Behavior, 4, 13-59.

Needham, J. (1942). Biochemistry and morphogenesis. Cambridge, UK: University Press.

Norris, V. (1998). Bacteria as tools for studies of consciousness. Em S. R. Hameroff, A. W. Kaszniak \& A. C. Scott (Orgs.), Toward a science of consciousness II (pp. 397-405). Cambridge: MIT Press.

Novikoff, A. B. (1945). The concept of integrative levels and biology. Science, 101, 209-215.

Oakley, D. A. (1985). Animal awareness, consciousness and self-image. Em D. A. Oakley (Org.), Brain and mind (pp. 132-151). London: Methuen.

Osgood, C. E. (1980). Lectures on language performance. New York: SpringerVerlag.

Polanyi, M. (1968). Life's irreductible structure. Science, 160, 1308-1312.

Pöppel, E. (1988). Mindworks (T. Artin, Trad. do alemão para o inglês). Boston: Harcourt Brace Jovanovich. (Original publicado em 1985) 
Popper, K. R. \& Eccles, J. C. (1977). The self and its brain. London: SpringerVerlag.

Prado e Silva, A. (Org.) (1970). Novo dicionário brasileiro Melhoramentos ilustrado. Vol. IV. São Paulo: Melhoramentos.

Radner, D. \& Radner, M. (1996). Animal consciousness. Amherst, NY: Prometheus.

Scheerer, E. (1994). Psychoneural isomorphism: Historical background and current relevance. Pbilosophical Psychology, 7, 183-210.

Schwartz, G. E. (1982). Psychophysiological patterning and emotion revisited: a systems perspective. Em C. E . Izard (Org.), Measuring emotions in infants and children. Cambridge, UK: Cambridge University Press.

Schwartz, G. E. (1996). Levels of awareness and "awareness without awareness": From data to theory. Em S. R. Hameroff, A. W. Kaszniak \& A. C. Scott (Orgs.), Toward a science of consciousness (pp. 279-298). Cambridge: MIT Press.

Scott, A. C. (1996). The hierarchical emergence of consciousness. Em S. R. Hameroff, A. W. Kaszniak \& A. C. Scott (Orgs.), Toward a science of consciousness (pp. 659-671). Cambridge: MIT Press.

Searle, J. R. (1992). The rediscovery of the mind. Cambridge: MIT Press.

Shu, F. H. (1994). The Cosmos. Em R. Mc Henry (Org.), New Encyclopedia Britannica. Macropaedia (Vol.16; pp. 762-796, 15 a ed.) Chicago: Encyclopaedia Britannica.

Smith, P. (1992). O que é ceticismo. São Paulo: Brasiliense.

Sommerhoff, G. (1990). Life, brain and consciousness. Amsterdam: North-Holland.

Sperry, R. W. (1969). A modified concept of consciousness. Psychological Review, 76, 532-536.

Sperry, R. W. (1983). Mind-brain interaction: Mentalism, yes; dualism, no. Em R.W. Sperry (Org.), Science and moral priority (pp. 77-103). Oxford: Basil Blackwell. (Original publicado em 1980)
Squyres, S. W. (1994). The solar system. Venus. Em The new encyclopaedia Brittanica (Vol. 27: pp. 469-477; 15 a ed.) Chicago: Encyclopaedia Brittanica.

Stadler, M. \& Kruse, P. (1994). Gestalt theory and synergetics: From psychophysical isomorphism to holistic emergentism. Philosophical Psychology, 7, 211-226.

Storer, T. I. (1951). General zoology (2a ed.). New York: McGraw-Hill.

Stubenberg, L. (1996). The place of qualia in the world of science. Em S. R. Hameroff, A. W. Kaszniak \& A. C. Scott (Orgs.), Toward a science of consciousness (pp. 41-49). Cambridge: MIT Press.

Tolman, E. C. (1951). Psychology versus immediate experience. Em E. C. Tolman (Org.), Behavior and psychological man. Berkeley: University of California Press. (Original publicado em 1935)

Tolman, E. C. (1967). Purposive behavior in animals and men. New York: Appleton-Century-Crofts. (Original publicado em 1932)

Underwood, G. (Org.) (1996). Implicit cognition. Oxford: Oxford University Press.

Weiskrantz, L. (1997). Consciousness lost and found. Oxford: Oxford University Press.

White, A. R. (1990). The language of imagination. Oxford: Basil Blackwell.

Whittaker, R. H. (1969). New concepts of kingdoms of organisms. Science, 163, 150-160.

Williams, B. (1983). Descartes's use of skepticism. Em M. Burnyeat (Org.), The skeptical tradition (pp. 337-352). Berkeley: University of California Press.
Sobre o autor:

Arno Engelmann é professor da Universidade de São Paulo.
Recebido em 6/06/2000

Revisado em 25/08/2000

Aceito em 26/09/2000 